\title{
Güneş Kollektörlü ve Elektrikli Şofbenli Bir Akıllı Evin Talep Cevabı Programı Kapsamında Enerji Yönetimi
}

\author{
Semanur Sancar ${ }^{1}$, Ayşe Kübra Erenoğlu ${ }^{1}$, İbrahim Şengör ${ }^{2 *}$, Ozan Erdinç ${ }^{1}$ \\ ${ }^{1}$ Yıldız Teknik Üniversitesi, Elektrik Elektronik Fakültesi, Elektrik Mühendisliği Bölümü , İstanbul, Türkiye (ORCID: 0000-0000-0000-0000) \\ 2 İzmir Katip Çelebi Üniversitesi, Mühendislik ve Mimarlık Fakültesi, Elektrik-Elektronik Mühendisliği Bölümü, İzmir, Türkiye (ORCID: 0000-0002-9451-4218)
}

(İlk Geliş Tarihi 27 Şubat 2020 ve Kabul Tarihi 23 Mayıs 2020)

(DOI: 10.31590/ejosat. 695784)

ATIF/REFERENCE: Sancar, S., Erenoğlu, A. K., Şengör, İ. \& Erdinç, O. (2020). Güneş Kollektörlü ve Elektrikli Şofbenli Bir Akıllı Evin Talep Cevabı Programı Kapsamında Enerji Yönetimi. Avrupa Bilim ve Teknoloji Dergisi, (19), 92-104.

\section{$\ddot{O} z$}

Modern dünyada enerji tüketiminin; dünya nüfusunun artması, bununla birlikte endüstriyel üretimin ivme kazanması ve teknolojinin gelişmesine bağlı olarak her geçen gün arttı̆̆ı gözlemlenmektedir. Enerji üretim alanında etkin olarak faydalanılan konvansiyonel sistemlerin kaynağını oluşturan fosil yakıtların dünya üzerinde heterojen dağılımı ve rezervlerin öngörülen ömürlerinin azalması alternatif kaynak arayışına neden olmuştur. Bu arayış sonucunda artış gösteren tüketim profilinin dengelenmesinde, yenilenebilir enerji sistemlerinin şebekeye entegrasyonu konusunda önemli adımlar atılmakla birlikte akıllı şebeke (Smart Grid) konseptinin en etkin uygulamalarından olan talep tarafının yönetimi (demand side management) gibi yeni mekanizmaların da dikkate alınması zorunlu hale gelmiştir. Enerji üretimi ve tüketiminin dengelenmesi, şebekenin düzgün işletimi açısından büyük bir öneme sahiptir ve doğası gereği değişken güç üretim profiline sahip bu sistemlerin üretim alanındaki payının artışı literatüre özellikle enerji yönetim sistemleri ve enerji verimliliği minvalinde yeni çalışmaların eklenmesinin önünü açmaktadır. Bu çalışmada; akıllı bir evin kritik yükleriyle birlikte termostatı kontrol edilebilir esnek yüklerden oluşan tüketim profili dikkate alınmıştır. Güneş kollektörü ve elektrikli şofbenden yararlanılan akıllı ev modeli için enerji yönetim sistemi geliştirilmiştir. Klima ve elektrikli şofbenden talep edilen gücün kontrolünde, iç ortam ve kazan suyu sıcaklıklarının kullanıcı konfor kısıtları dikkate alınarak belirli değer aralıklarında tutulması sağlanmıştır. Özellikle talep cevabı (Demand Response) programı uygulanırken kullanıcının konfor sınırlarının aşılmamasına dikkat edilmesi çalışmanın en önemli özelliklerindendir. Geliştirilen model ile ilgili akıllı evin elektrik enerjisi tüketim maliyetinin minimize edilmesi amaç fonksiyonunu oluşturmuş ve elde edilen sonuçlar ile optimizasyon tabanlı yaklaşımın değerlendirilmesi detaylı olarak gerçekleştirilmiştir. Karmaşı tam sayılı lineer programlama yöntemi (Mixed Integer Linear Programming-MILP) ile geliştirilen matematiksel modelleme, Python 2.7 versiyonunun PuLP 1.6.8 açık kaynak kodlu kütüphanesi içinde CPLEX ticari optimizasyon çözücüsünden faydalanılarak benzetim çalışması gerçekleştirilmiştir.

Anahtar Kelimeler: Akıllı şebeke, talep cevabı, yenilenebilir enerji sistemleri.

\section{Energy Management Model of a Smart House with Solar Collector and Electric Water Heater Considering Demand Response}

\begin{abstract}
In the modern world, there is an increase in energy consumption associated with population growth, acceleration of industrial production and the development of technology. The heterogeneous distribution of fossil fuels, which constitute the source of conventional systems that are used effectively in the field of energy production, and the decrease of the predicted lifetimes of the reserves, have led to the search for alternative sources. To keep in the balance of the increasing consumption profile, important steps have been taken regarding the integration of renewable energy systems into the network, and new mechanisms such as the management of the demand side, which is one of the most effective applications of the smart grid concept, have become necessary. Equilibration energy production and
\end{abstract}

* Sorumlu Yazar: İzmir Katip Çelebi Üniversitesi, Mühendislik ve Mimarlık Fakültesi, Elektrik-Elektronik Mühendisliği Bölümü, İzmir, Türkiye, ORCID: 0000-0002-9451-4218, ibrahimsengor.is@gmail.com 


\section{European Journal of Science and Technology}

consumption has great importance in terms of proper operation of the network and due to its nature, the increase in the share of renewable energy systems with variable power generation profile in the production field paves the way for adding new studies to the literature, especially in terms of energy management systems and energy efficiency. In this study; consumption profile consisting of flexible loads whose thermostat can be controlled together with critical loads of a smart home has been taken into consideration. The energy management system has been developed for the smart home model that uses the solar collector and the electric water heater(EWH). In controlling the power demand of the air conditioner (AC) and EWH, it was ensured that the indoor and boiler water temperatures were kept within certain value ranges by paying attention to the user comfort constraints. It is one of the most important features of the study to be careful not to exceed the comfort limits of the user while applying the Demand Response Program (DRP). The minimizing the cost of electricity consumption of the smart house is determined as the purpose function in the developed model and the results have been evaluated in detail with an optimization-based approach. The mathematical formulation obtained by the mixed-integer linear programming(MILP) method was simulated in the PuLP 1.6.8 open source library of the Python 2.7 version using the CPLEX commercial optimization solver.

Keywords: Smart grid, demand response, renewable energy systems.

\section{ADLAR DİíNi}

\section{A. Kümeler}

$t \quad$ Zaman Kümesi [sa.].

\section{B. Parametreler}

$\lambda_{t}^{\text {fiyat }} \quad$ Şebekeden satın alınan gücün anlık birim fiyatı [TL/kWh].

$m_{h} \quad$ Havanın a

$m_{s} \quad$ Kazan suyu ağırlı̆̆ $\left.1 \mathrm{~kg}\right]$.

$m_{t} \quad$ Tüketilen sıcak su karşılığında sisteme eklenen soğuk su ağırlığı [kg].

$c_{a} \quad$ Havanın 1 si kapasitesi $\left[\mathrm{kJ} / \mathrm{kg}^{\circ} \mathrm{C}\right]$.

$c_{p} \quad$ Suyun öz $1 \mathrm{~S} 1 \mathrm{~s} 1\left[\mathrm{Ws} / \mathrm{kg}^{\circ} \mathrm{C}\right]$.

$R^{e s ̧} \quad$ Eşdeğer termal direnç $\left[\mathrm{s}^{\circ} \mathrm{C} / \mathrm{J}\right]$.

$T_{t}^{h} \quad$ Diş ortamın anlık hava sıcaklığ $\left[{ }^{\circ} \mathrm{C}\right]$.

$T_{t}^{t} \quad$ Anlık tüketilen sicak su sicaklığ $\left[{ }^{\circ} \mathrm{C}\right]$.

$T_{t}^{s} \quad$ Sisteme dahil olan soğuk su sıcaklığ $\left[{ }^{\circ} \mathrm{C}\right]$.

$T_{t}^{k, s, \min } \quad$ Minimum kazan suyunun sicaklığ $\left.1{ }^{\circ} \mathrm{C}\right]$.

$T_{t}^{k, s, \max } \quad$ Maksimum kazan suyunun sicaklı $\breve{g}_{1}\left[{ }^{\circ} \mathrm{C}\right]$.

COP Performans verimliliği.

$R_{k} \quad$ Klimanın anma gücü [kW].

$S P_{t} \quad$ Klimanın ayarlanan sicaklık noktası [ $\left.{ }^{\circ} \mathrm{C}\right]$.

$S_{t}^{d} \quad$ Minimum oda sicaklığının ayarlanan değerden sapma miktarı $\left[{ }^{\circ} \mathrm{C}\right]$.

$S_{t}^{u} \quad$ Maksimum oda sıcaklığının ayarlanan değerden sapma miktarı $\left[{ }^{\circ} \mathrm{C}\right]$.

$Q_{t}^{g u ̈ n e s ̧} \quad$ Güneş kollektöründen suya aktarılan güç miktarı [kW].

$Q_{c} \quad$ Elektrikli şofbenin anma gücü [W].

$U \quad$ Kazan ve hava arasındaki 1sı kaybı katsayısı $\left[\mathrm{W} / \mathrm{m}^{2}{ }^{\circ} \mathrm{C}\right]$.

$U_{l} \quad$ Güneş kollektörü ve hava arasındaki 1sı kaybı katsayısı $\left[\mathrm{W} / \mathrm{m}^{2}{ }^{\circ} \mathrm{C}\right]$.

$A \quad$ Kazan toplam yüzey alanı $\left[\mathrm{m}^{2}\right]$.

$A_{c} \quad$ Güneş kollektörü yüzey alanı $\left[\mathrm{m}^{2}\right]$.

$F_{r} \quad$ Güneş kollektörü 1sı soğurma faktörü.

$S_{t} \quad$ Güneş 1 şıması $\left[\mathrm{W} / \mathrm{m}^{2}\right]$.

$\Delta T \quad$ Zaman çözünürlüğü [s].

$L_{t} \quad$ Evin esnek olmayan yükleri [kW]. 
$\begin{array}{ll}A_{i} & \text { Element yüzey alanı }\left[\mathrm{m}^{2}\right] . \\ l_{i} & \text { Element kalınlığ }[\mathrm{m}] . \\ \sigma_{i} & \text { Element termal verimliliği }\left[\mathrm{J} / \mathrm{h} . \mathrm{m} .{ }^{\circ} \mathrm{C}\right] . \\ V_{e v} & \text { Akıllı ev hacmi }\left[\mathrm{m}^{3}\right] .\end{array}$

\section{Değişkenler}

$\begin{array}{ll}P_{t}^{\text {șebeke }} & \text { Şebekeden çekilen anlık güç }[\mathrm{kW}] . \\ P_{t}^{K} & \text { Klimanın çektiği anlık güç }[\mathrm{kW}] . \\ P_{t}^{E S ̧} & \text { Elektrikli şofbenin çektiği anlık güç }[\mathrm{kW}] . \\ T_{t}^{o} & \left.\text { Oda sıcaklığ } 1{ }^{\circ} \mathrm{C}\right] . \\ T_{t}^{k, S} & \text { Kazan suyu sıcaklığ }\left[{ }^{\circ} \mathrm{C}\right] . \\ u_{t}^{K} & \text { Klima için ikili değişken; çalışıyorsa } 1 \text {, çalışmıyorsa } 0 . \\ u_{t}^{E S} & \text { Elektrikli şofben için ikili değişken; çalışıorsa } 1 \text { çalışmıyorsa } 0 .\end{array}$

\section{Giriş}

\subsection{Motivasyon ve Geçmiş Çalışmalar}

Yapılan tahminlere göre elektrik enerjisi tüketimi 2050 yılına kadar \%50 oranında artış gösterecektir (McKinsey \& Company, 2019). $\mathrm{Bu}$ talebe optimum şekilde cevap verebilmek güç sistem operatörleri için oldukça önemli bir konu başlı̆̆ haline gelmiştir. Petrol, doğalgaz ve kömür gibi konvansiyonel enerji santrallerinde kullanılan fosil yakıt rezervlerinin sınırlı olması farklı kaynakların arz tarafına entegrasyonunu zorunlu kılmıştır. Bu yönelimler sonucunda rüzgar enerjisi, güneş enerjisi (photovoltaic- PV), biyoenerji gibi yenilenebilir kaynaklı alternatif enerjili elektrik sistemlerin yaygınlaşması üzerinde çalışılmaktadır. Uluslararası Enerji Ajansı’nın (International Energy Agency-IEA) Yenilenebilir 2019 raporuna (REN21, 2019) göre 2019-2024 zaman dilimi için yapılan planlamalarla, dünya çapında PV sistemler başta olmak üzere yenilenebilir güç sistemleri kapasitesinin $1100 \mathrm{GW}$ 'lık artış seviyesini bulması öngörülmektedir. $\mathrm{Bu}$ artışın günümüz Amerika Birleşik Devletleri'nin kurulu güç kapasitesine eşdeğer olduğu söylenebilmektedir. Şekil 1'de yenilenebilir enerji sistemleri kaynak bazlı kapasite artışı, Şekil 2'de ise 2018-2024 yılları arasında ülke ve bölgelere göre tahmin edilen dağılım gösterilmiştir. Şekil 1'de IEA raporuna göre dağıtık güneş enerjisi sistemlerinin tahmin edilen gelişimi dikkat çekmektedir (REN21, 2019). PV sistemlerindeki bu gelişim potansiyeli hem enerji hem 1sıtma sistemlerinde maliyetsiz kaynak olarak güneşten daha fazla faydalanılabileceğini göstermektedir.

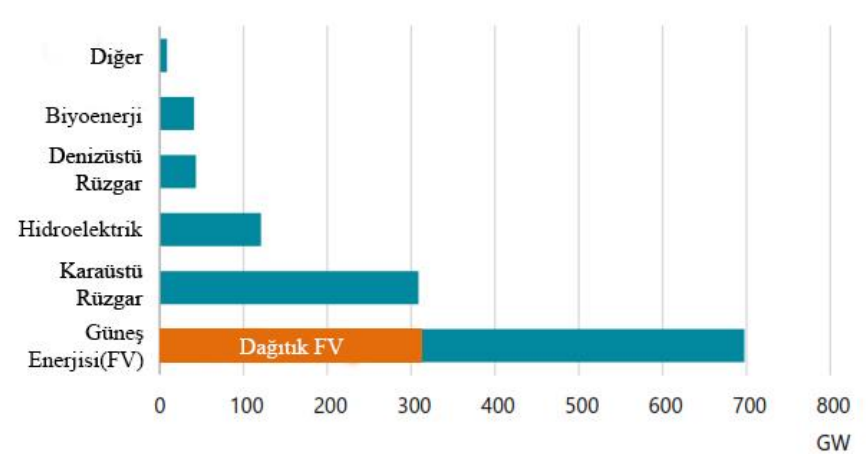

Şekil 1. Kaynaklarına Göre Yenilenebilir Enerji Sistemlerinin 2019-24 Aralı̆̆ında Tahmin Edilen Artış Kapasiteleri

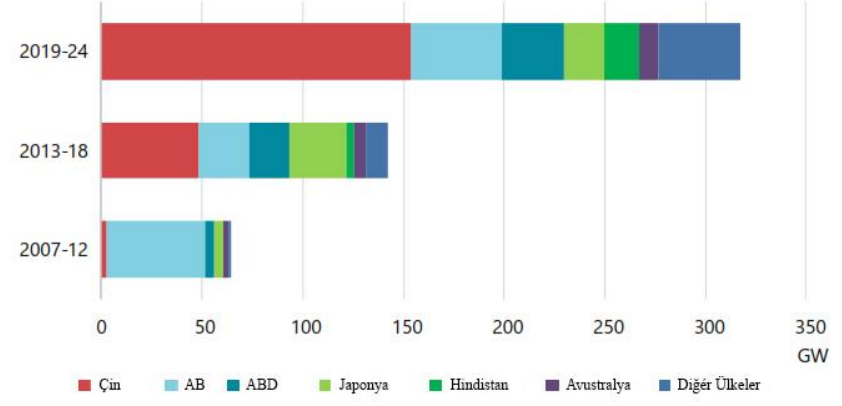

Şekil 2. Ülkelere Göre Yenilenebilir Enerji Sistemlerindeki Dönemsel Gelişim Kapasiteleri ve Tahminleri

Yine aynı rapora göre Çin'deki gelişim belirlenen tahmin süresi içinde küresel yenilenebilir kapasite artışının \%40’ını oluşturmaktadır (REN21, 2019). Çin'in bu paya sahip olmasındaki en temel faktör PV üretiminin ve rüzgar enerjisinde faydalanma oranının yüksek olması sağlamaktadır. Avrupa Birliği için öngörülen sonuçlar, üye ülkelerin dağıtık PV sistemleri üzerine geliştirdiği politikalar ve koymuş olduğu hedefler ile doğru orantılıdır. Amerika Birleşik Devletlerin'de öngörülen kapasite artışı da federal vergi teşvik düzenlemeleri ile gelişim göstermektedir.

Yenilenebilir enerji sistemlerinin gelişmesiyle birlikte talep tarafının yönetimi de çalışılan popüler konulardan birisi haline gelmiştir. Dünya çapında farklı ülkelerde esnek fiyat tarifesi (Triki ve Violi, 2009; Schreiber vd., 2015; Chiu vd., 2017), talep tarafının yönetimi için verilen teşvikler (Alvina vd., 2017; Mahin vd., 2017) ve akıllı ev enerji yönetim sistemleri (Santos vd., 2018; Zhou vd., 2018; Koltsaklis vd., 2019) gibi kavramlar hem çalışma hem uygulama sahası bulmaya başlamıştır. Geçmişten günümüze hali hazırda mevcut güç sistemi problemlerinin yanında yenilenebilir enerji sistemlerinden kaynaklı işletme sorunlarının da eklenmesi şebeke operasyonel 


\section{European Journal of Science and Technology}

faaliyetlerinin gelişimini zorunlu kılmıştır. Talep tarafı yönetim sistemlerinin temel amacı sadece üretim tarafının değil son kullanıcı davranışlarını değiştirerek tüketimin esnekliğinden de faydalanmaktır. Siano (2014), Behrangrad (2015), Gaur (2016), Hungerford vd. (2016) ve Meyabadi vd. (2017) tarafından gerçekleştirilen çalışmalarda da üzerinde durulduğu gibi talep tarafı yönetimi; yük kaydırma hareketleri ile pik zamanlardaki aşırı yüklenmeyi minimize edip üretim-iletim-dağıtım maliyetlerini ve süreç boyunca karbon emisyonunu azaltarak enerji verimliliği, enerji sürdürülebilirliği ve enerji güvenilirliği sağlamaktadır.

Özellikle akıllı şebeke konsepti 1şı̆̆ında uygulanması planlanan talep tarafındaki aksiyomların gelişimi için ciddi bir haberleşme altyapısı kurulmalı ve otomasyonla desteklenmelidir. Enerji yönetimi sistemlerinin kurulumu ve kablosuz bilgi alışverişine olanak sağlayan teknolojilerin düzgün bir şekilde işletimi detaylı olarak irdelenmelidir. Üretim yanında hem tüketim hem de dinamik fiyatlandırmanın takip edildiği ve anlık optimal çözümler geliştirildiği sistemlerin yaygınlaştı̆̆ı görülmektedir. Güngör vd. (2011) gerçekleştirdiği çalışmada 100 yıllardır yapısı neredeyse aynı olarak kullanılan elektrik şebekelerinin verimlilik, güvenilirlik, kontrol mekanizmalarının ve ölçüm sistemlerinin gelişmesi gibi sebeplerle akıllı şebekelere dönüşümü üzerinde durularak, akıllı şebekeler için geliştirilen haberleşme teknolojileriyle ilgili araştırma alanlarına parmak basılmıştır. Erol-Kantarci ve Mouftah (2011) yayınladığ çalışmada yeni nesil şebekeler için bilgi ve haberleşme teknolojilerinin (Information and Communication Technologies- ICT) önemine değinilerek kablosuz multimedia sensörler ve ağlar üzerinde durulmuştur. Mohsenian-Rad ve Leon-Garcia (2010) tarfından yayınlanan çalışmada ise gerçek zamanlı fiyatlandırma sistemi kullanılarak oluşturulnuş bir enerji yönetim yaklaşımı mevcuttur. Bu gibi çalışmaların ICT’nin gelişmeleri üzerine bina edildiği görülmektedir.

Akıllı şebekeler ve akıllı evler sayesinde artık son kullanıcıların aktif bir oyuncu olarak piyasada rol alabilmesi, kendi üretim tüketim dengesini sağlayabilmesi ve yükünü kontrol edebilmesi dağıtım şirketleri ile kullanıcılar arasında talep tarafı cevabı (Demand Side Response -DSR) adı altında yapılan anlaşmalara da bağlıdır. Son kullanıcı perspektifinden bakıldığında; 1sıtma, soğutma ve klima sistemlerinin (Heating, Vantilating and Air Conditioning - HVAC) güç tüketim grafiğinde \%40'a varan büyük bir paya sahip olduğu çeşitli araştırmalarla ortaya konulmuştur (Jouhara ve Yang, 2018). Bununla birlikte literatürde gerçekleştirilen diğer bir araştırmada Birleşik Krallık'taki tipik bir evin ortalama olarak günlük talep eğrisi Şekil 3’te gösterildiği gibidir (Ovoenergy). Talep tarafı yönetimi ve enerji tüketimi kontrolü ile HVAC'lar üzerinde sağlanabilecek enerji verimliliği potensiyeli Perez vd. (2016) ve Cai vd. (2019) çalışmalarında araştırma konusu olmuştur. Amerika Birleşik Devletleri gibi talep tarafi yönetim sistemlerinin hayat bulduğu ülkelerde dağıtım şirketleri ile kullanıcılar arasında yapılan anlaşmalar neticesinde HVAC sistemlerinin kontrolüyle ilgili örnekler mevcuttur (ComEd; Sempra Energy Utility). HVAC'lar ile birlikte sıcak su ihtiyacını karşılamak üzere kullanılan bir diğer sistem elektrikli şofbenlerdir (Electric Water Heater-EWH). Bu 1sıtıcıların enerji yönetim sistemlerine entegrasyonu termostatı ayarlanabilir olarak geliştirilen yeni teknoloji ürünler ile gerçekleştirilebilmektedir. Dinamik fiyatlandırma altında EWH kontrolü sağlayan bir yaklaşım çalışmalarda mevcuttur (Goh ve Apt, 2005).

Sıcak su ihtiyacını karşılamada kullanılan başka bir sistem ise güneş kollektörleridir. Bu sistemler karbon emisyonu üreten konvansiyonel kaynaklara veya elektrik tüketimine ihtiyaç duymadan ev içi sıcak su ihtiyacını karşılamak üzere kullanılmaktadır. Gautam vd. (2017) sahibi olduğu referansta yer alan verilere göre su 1sıtmada kullanılan enerjinin bütün tüketime oranı Amerika Birleşik Devletlerinde \%18.3, Avustralya'da \%25, Kanada'da \%22, Avrupa'da \%14, Güney Amerika'da \%37, Çin'de \%27 ve Meksika'da \%29'dur. Bahsi geçen çalışmada, güneş kollektörlerinin yüksek kurulum maliyeti gibi olumsuz yanlarına karşılık güneşin 1sıtma enerjisindeki kullanılabilir potansiyeli ve ısıtmada kullanılan diğer kaynakların maliyetleri üzerinde değerlendirmelerde bulunularak dünya çapında güneş kollektörlerinin geleceği ile ilgili senaryolar oluşturulmuştur.
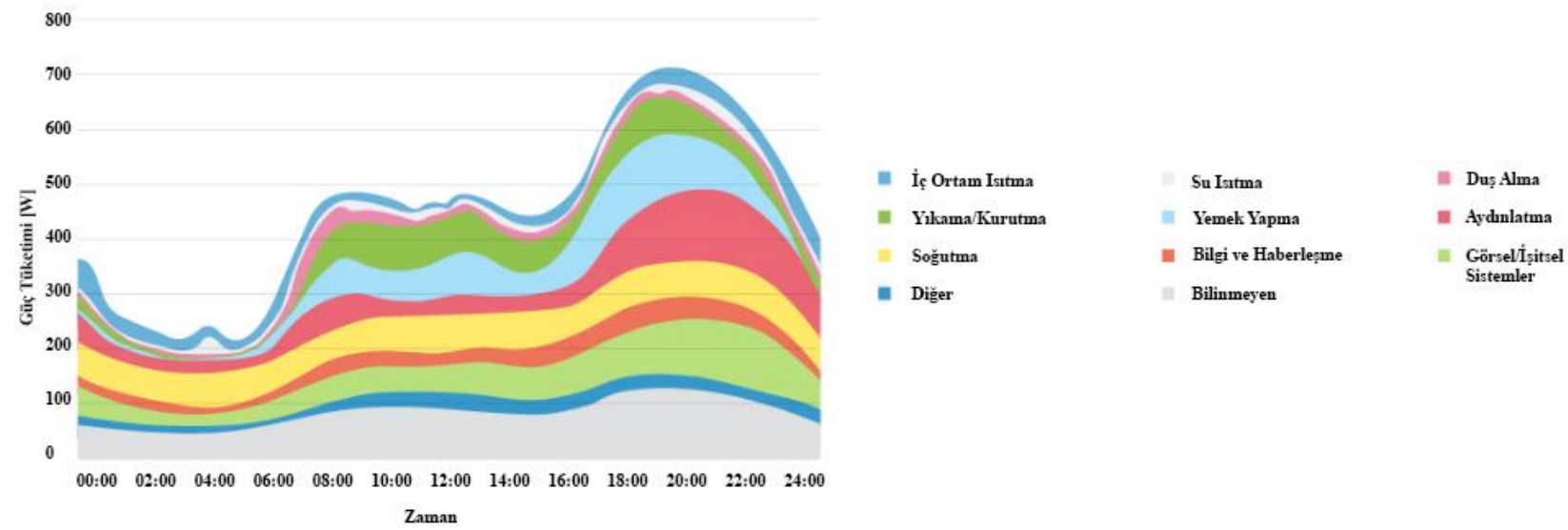

Şekil 3. Tipik Bir Birleşik Krallık Evinde 24 Saatlik Ortalama Elektrik Kullanımı.

Ev enerji yönetim sistemleriyle (Home Energy Management-HEM) ile ilgili şimdiye kadar yapılan çalışmalarda birçok yaklaşım mevcuttur. Bu çalışmalar genellikle kontrol edilebilir yükler ve kullanılan enerji kaynakları açısından farklılık göstermektedir. Yükleri ötelenebilirlik-bölünebilirlik-programlanabilirlik özellikleri açısından değerlendiren Tsui ve Chan (2012), Zhi vd. (2012), ve Pipattanasomporn vd. (2016) gerçekleştirdiği çalışmalarda HEM sistemleri için optimizasyon ve yapay sinir ağları gibi çözümler içeren 


\section{Avrupa Bilim ve Teknoloji Dergisi}

yaklaşımlar geliştirilmiştir. Lokeshgupta ve Sivasubramani (2019) enerji depolama sistemini (Energy Storage System-ESS) sisteme dahil ederek kontrol edilebilir yükleri kullanıcı önceliklerine göre DR programını da dikkate alan optimizasyon tabanlı bir çözüm sunmuştur. Enerji üretim tarafında PV panelleri dikkate alan çalışmada yükler; bölünebilir-bölünemez-zamana bağlı olarak kategorize edilerek DR programına entegre edilmiştir ve yine optimizasyon bazlı bir yaklaşım geliştirilmiştir (Yao, Damiran ve Lim, 2017). Bir diğer çalışmada ise hem PV panellerin hem de ESS'nin enerji yönetim stratejisi geliştirilirken esneklik kaynağı olarak kullanılması hedeflenmiş ve programlanabilir elektrikli evsel yüklerin DR programı kapsamında değerlendirildiği bir çalışma önerilmiştir (Yao, Shen ve Lim, 2017).

HVAC sisteminden ev içi soğutma ihtiyacının karşılanmasında faydalanılması ve bu şekilde termal yüklerin kontrol edilerek optimizasyon tabanlı bir çalışma gerçekleştirilmiştir. Bu noktada, evin yapısal ve termal özelliklerinin değerlendirilmesi sağlanmıştır (Wang vd., 2013). Diğer taraftan, HEM için kontrol edilebilir termal yük olarak EWH'nin belirlenmesi ve yük öteleme stratejilerinin etkinliğinin araştırılması çalışmanın konusu olmuştur (Ali vd., 2019). Ahmed vd. (2016) ve Safdarian vd. (2016) enerji yönetim sisteminde termal yükleri kontrol etme fikri öne sürmüşlerdir. Yapılan çalışmalarda HVAC ve EWH yüklerinin kontrolü DR programı kapsamında optimum cevap elde etmede faydalanılmıştır. HEM için esneklik sağlayan PV üretimini göz önünde bulundurarak HVAC kontrolü öneren ve şebeke işletimine katkı sağlayan çalışmalar da ortaya konulmuştur (Godina vd., 2017; Godina vd., 2018).

Güneş kollektörlerinin yapısı, açısı ve işletim optimizasyonu gibi konularda (Facão, 2016; Streicher, 2016; Freegah ve Tabbakh, 2019) gibi çalışmalar mevcuttur. Ancak HVAC ve EWH'nin yük kontrolü optimizasyonunda beraber değerlendirildiği ve güneş kollektörünün EWH yükünü azaltıcı şekilde 1sı saklama birimindeki sıcaklı̆̆ kullanıcının istediği değerlerde tutarak evin sıcak su ihtiyacını karşılamak üzere düşünülmüş bir çalışma bulunmamaktadır.

\section{2. Çalışmanın Katkıları}

$\mathrm{Bu}$ çalışmada, akıllı bir evin ısınma ve sıcak su ihtiyacının karşılanması aynı zamanda talep yönetimine katılımının sağlanması amacıyla geliştirilen sistem karmaşı tamsayılı lineer programlama (Mixed Integer Linear Programming-MILP) kullanılarak matematiksel olarak modellenmiştir. Geliştirilen optimizasyon tabanlı karar verme algoritmasında amaç fonksiyonu evsel kullanıcının enerji maliyetini minimize edecek şekilde belirlenmiştir. Çalışmanın katkıları aşağıdaki gibi sıralanabilir:

1) Geliştirilen optimizasyon tabanlı modelde kullanıcı konfor kısıtlarının aşılmaması sistem kısıtı olarak belirlenmiştir.

2) Güneş kollektörü ve elektrikli şofben sayesinde evin ısınmada kullanılan enerji talebi karşılanmaktadır. Yine özellikle kış aylarında artış gösteren sıcak su ihtiyacının da dikkate alınmasıyla yenilebilir bir kaynak olan güneşten yararlanılmışır.

3) Klima yükünün kontrol edilmesiyle talep tarafı yönetimi stratejisi geliştirilmiştir. Optimum kararlar uygulanırken kazan ve iç ortam sıcaklı̆̆ının muhakkak belirlenen sınırlar arasında olması sağlanmıştır.

Önerilen sistemdeki elemanların tanıtılması, sistemin çalışma mantığı ve matematiksel formülasyonun adımları Bölüm 2'de, Python programında CPLEX çözücü ile yapılan test ve analizlerin sonuçları ise Bölüm 3’te anlatılmıştır. Elde edilen kapsamlı sonuçlar Bölüm 4'te detaylı bir şekilde irdelenmiş ve sunulmuştur.

\section{Metodoloji}

\subsection{Sistemin Genel Tanımı}

Tasarlanan akıllı enerji yönetim modelinin görselleştirilmiş hali Şekil 4'te verilmiştir. Şebekeden elektrik enerji talebini karşlayan evsel kullanıcının sıcak su talebi güneş kollektörü ve elektrikli şofben tarafından (belli bir sıcaklık aralığında tutulan kazan suyundan) karşılanmaktadır. İç ortam sıcaklığı (oda sıcaklı̆̆ı) ise klima sistemi tarafından kullanıcının ayarladığı eşik noktaları arasında tutulmaktadır. Böylece talep tarafındaki profil değiştirilirken kullanıcı konfor kısıtları dikkate alınmış olur.

Geliştirilen enerji yönetim sistem algoritmasının akış diyagramı Şekil 5’te gösterilmişstir. Buna göre, modelleme gerçekleştirilirken evsel yüklerin tüketim verileri, ışıma değerleri ile güneş kollektörünün özellikleri, elektrikli şofben verisi ve dinamik fiyatlandırma giriş veri setini oluşturmaktadır. Karmaşık tam sayılı lineer programlama ile modellenen sistemde bir sonraki adımda değişkenler belirlenmektir. Özellikle talep cevabı programına katılan esnek yüklerin çalışma periyotları ve toplam maliyet bağımsız değişkenlerdendir. PuLP Python kütüphanesinde modellenen ve ticari CPLEX çözücüsü yardımıyla çözülen problemin nümerik çıktıları bu sayede elde edilmektedir. Kullanıcı konfor kısıtları aşılmadan maliyetin minimizasyonu sağlanmaktadır.

Güneş kollektörünün ısınma durumu, dış ortam sıcaklığı, oda ve kazan suyu sıcaklıkları gibi verilerin çeşitli sensörlerle işlenerek enerji yönetim sistemine ulaştırıldığı kabul edilmiştir. Gün öncesi piyasası fiyatlandırma sinyalleri ve fatura takibinin ise enerji yönetim sistemine akıllı sayaç vasıtasıyla ulaştıııldığı varsayılmıştır. Yani akıllı sayaç sayesinde şebekeyle çift yönlü hem bilgi hem de enerji alışverişi gerçekleştirilebilmektedir. 


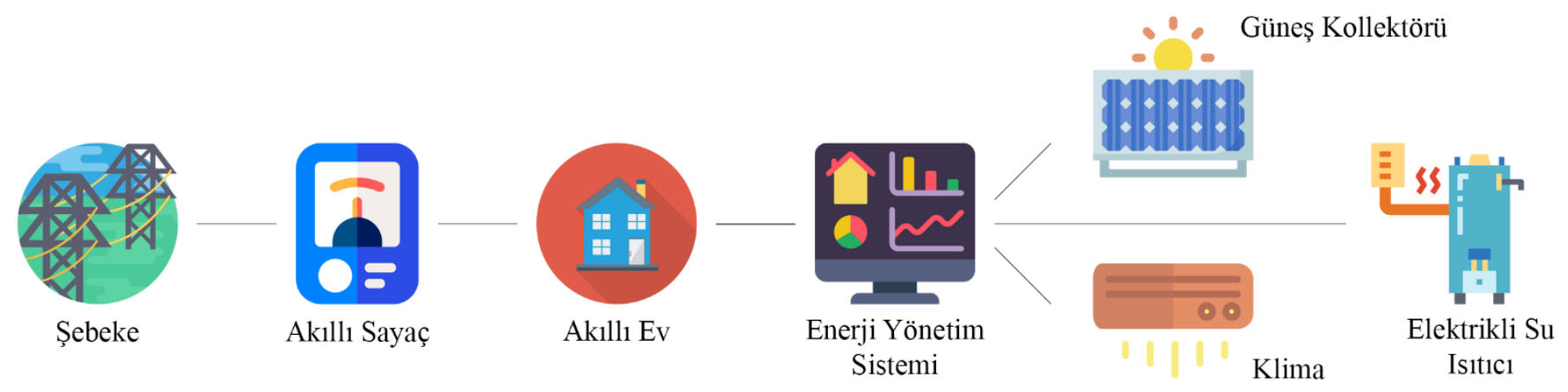

Şekil 4. Tasarlanan Akıllı Ev Modelinin Şematik Gösterimi

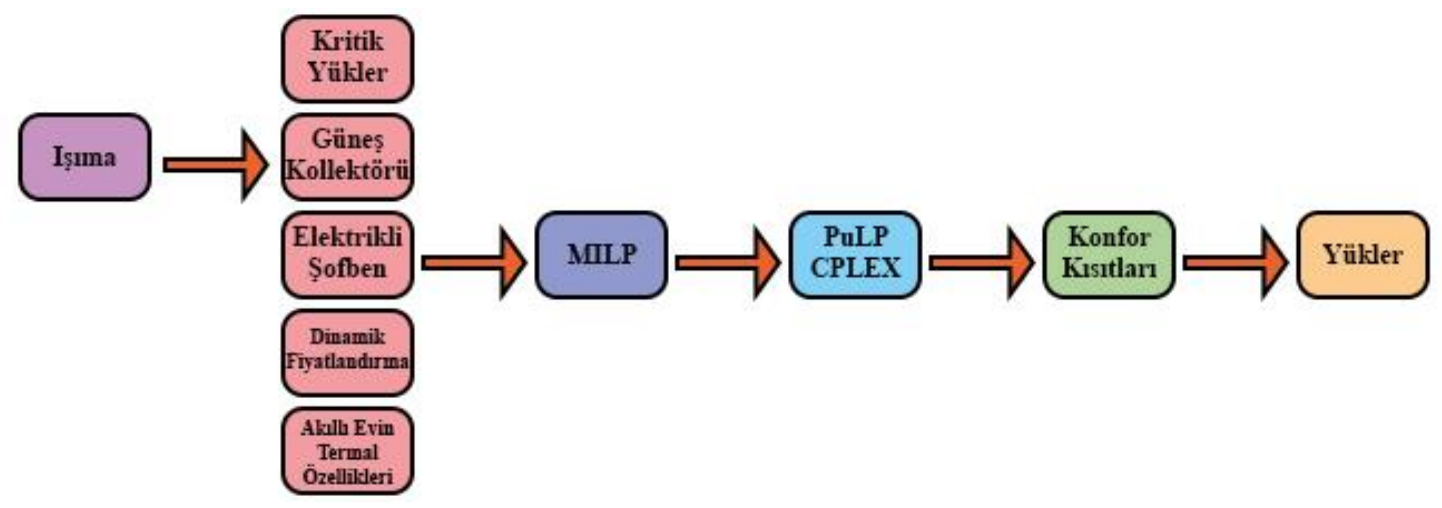

Şekil 5. Enerji Yönetim Sisteminin Algoritma Akış Diyagramı

\subsection{Matematiksel Formülasyon}

Akıllı bir evin optimum koşullarda işletiminin sağlanması ve bu bağlamda enerji maliyetinin minimize edilmesi optimizasyon tabanlı algoritmanın amaç fonksiyonunu oluşturmaktadır. Toplam maliyet, Eşitlik (1)'de gösterildiği üzere şebekeden $t$ periyodu boyunca çekilen güç $\left(P_{t}^{\text {sebeke }}\right)$ ile birim enerji fiyatının $\left(\lambda_{t}^{\text {fiyat }}\right)$ çarpılmasıyla elde edilmektedir.

$$
\text { Minimum Maliyet }=\sum_{t} P_{t}^{\text {sebeke }} \cdot \Delta T \cdot \lambda_{t}^{\text {fiyat }}
$$

Klimanın 1sıtma modunda çalışması durumundaki dinamikleri modellenirken göz önünde bulundurulan termodinamik denklemler, (Paterakis vd., 2015)'de sunulan çalışma baz alınarak elde edilmiştir. Denklem (2)-(4), modelin bu çalışmaya uyarlanmış halini göstermektedir. Talep cevabı kaynağı olarak kullanılan klimalar özellikle pik saatlerde tüketim azaltılması noktasında yardımcı servis elemanı olarak değerlendirilebilir. Termal yük modeli kullanılan bu çalışmada, Denklem (2)'de gösterildiği üzere iç ortam sıcaklı̆̆ $\left(T_{t+1}^{o}\right)$; bir periyot önceki iç ortam sıcaklığına $\left(T_{t}^{o}\right)$, dış ortam sıcaklığına $\left(T_{t}^{h}\right)$, akıllı evin eşdeğer termal direncine $\left(R^{e s}\right)$ bağlı olarak değişmektedir. Klima, enerji verimliliği açısından oda sıcaklığı belirlenen limitin altına düşecek olursa çalışacak şekilde optimizasyon problemi geliştirilmiş ve böylece gereksiz enerji tüketimin önüne geçilmiştir. Eşitlik (3) sayesinde iç ortam sıcaklığı kullanıcı tarafından belirlenerek bu sıcaklı̆ğın alt ve üst konfor sınırları dâhilinde olması zorunlu kılınmıştır. Böylece kullanıcının konfor kısıtlarını dikkate alan bir talep cevabı programı uygulanmaktadır. Denklem (4)'te ise klimanın çalışması durumunda şebekeden çekeceği güç $\left(P_{t}^{K}\right)$ tanımlanmaktadır. Burada $u_{t}^{K}$ ikili değişkeni klimanın çalışma durumuna karar vermektedir.

$$
\begin{gathered}
T_{t+1}^{o}=\left(1-\frac{\Delta T}{10^{3} \cdot m_{h} c_{a} R^{e s}}\right) T_{t}^{o}+\frac{\Delta T}{10^{3} \cdot m_{h} c_{a} R^{e s ̧}} T_{t}^{h}+\frac{C O P \cdot R_{k} \cdot \Delta T}{0,000277 \cdot m_{h} c_{a}} u_{t}^{K} \quad, \quad \forall t \\
S P_{t}-S_{t}^{d} \leq T_{t}^{o} \leq S P_{t}+S_{t}^{u} \quad, \quad \forall t: S P_{t} \neq N a N \\
P_{t}^{K}=R_{k} \cdot u_{t}^{K} \quad, \quad \forall t
\end{gathered}
$$

Güneş kollektörü ve elektrikli şofben evin sıcak su ihtiyacını karşılamada hibrit olarak kullanılacağından dolayı Medeiros vd. (2013) tarafından tanımlanmış ısı dinamikleri baz alınarak kazan sıcaklığının hesaplanması gerekmektedir. Bu modelin akıllı eve uyarlanmış hali Denklem (5)-(7) ile gösterilmiştir. Kazan suyunun sıcaklığ $\left(T_{t+1}^{k, s}\right)$; güneş kollektörünün suya aktaracağı güç $\left(Q_{t}^{g u ̈ n e s}\right)$, elektrikli şofbenin anma gücü $\left(Q_{c}\right)$, kullanılan sıcak suya karşılık kazana eklenecek soğuk suyun kütlesi $\left(m_{t}\right) /$ sicaklığı $\left(T_{t}^{S}\right)$ ve kayıpların etkileri 
göz önünde bulundurularak Eşitlik (5) yardımıyla hesaplanabilmektedir. Eşitlik (6) sayesinde kazan suyunun sıcaklığı konfor ve güvenlik sınırları içerisinde tutulmaktadır. Elektrikli şofbenin çalıştığı anlarda şebekeden çekeceği yük miktarı $\left(P_{t}^{E S}\right)$ Denklem (7) ile ifade edilmiştir. Güneş kollektörünün suyu ısıtırken suya aktardığı güç miktarı (Kalogirou, 2009, Eq. 3.76)'da yapılan hesaplamalar ışı̆̆ında anlık güneşlenme miktarı $\left(S_{t+1}\right)$, kollektörün ısı soğurma faktörü $\left(F_{r}\right)$ ve kayıplar değerlendirilerek (8) numaralı denklemdeki gibi hesaplanmıştır.

$$
\begin{gathered}
T_{t+1}^{k, s}=T_{t}^{k, s}+\frac{Q_{t}^{g \text { ünes }} \cdot \Delta T}{m_{s} c_{p}}+\frac{10^{3} \cdot Q_{c} \cdot \Delta T}{m_{s} c_{p}} u_{t}^{E S I}-\frac{(U \cdot A) \cdot \Delta T \cdot\left(T_{t}^{k, s}-T_{t}^{h}\right)}{m_{s} c_{p}}-\frac{m_{t}\left(T_{t}^{t}-T_{t}^{S}\right)}{m_{s}}, \quad \forall t \\
T_{t}^{k, s, m i n} \leq T_{t}^{k, s} \leq T_{t}^{k, s, \max }, \quad \forall t \\
P_{t}^{E S}=Q_{c} \cdot u_{t}^{E S,}, \forall t \\
Q_{t+1}^{g \text { ünes }}=A_{c} F_{r}\left[S_{t+1}-U_{l}\left(T_{t}^{k, s}-T_{t}^{h}\right)\right], \quad \forall t
\end{gathered}
$$

Şebekeden akıllı ev kritik yükleri $\left(L_{t}\right)$ ve önerilen 1sıtma sistemleri için kullanılan güç miktarları anlık olarak Eşitlik (9)'daki güç dengesini oluş̧urmaktadır. Kullanılan eşitlikler lineer programlama yapısı baz alınarak oluşturulduğundan dolayı, gerçek zamanlı olarak test yapabilmeyi sağlayan uygulama platformları için uygundur.

$$
P_{t}^{\text {sebeke }}=L_{t}+P_{t}^{K}+P_{t}^{E S} \quad, \quad \forall t
$$

\section{Araştırma Sonuçları ve Tartışma}

\subsection{Giriş Verileri}

Geliştirilen matematiksel model Python 2.7 versiyonu kullanılarak test edilmiştir. Python, gelişen teknolojiyle beraber çok çeşitli alanlarda kullanımı kolay, ticari ve açık kaynak kodlu olmak üzere algoritma kütüphaneleri sunmakta olan bir yazılım dilidir. Aynı zamanda farklı programlar ile entegre olarak veri alışverişi sağlama kolaylığı sunmaktadır. Bu çalışmada, MILP ile oluşturulmuş optimizasyon problemini gerçeklemek üzere açık kaynak kodlu PuLP 1.6.8 kütüphanesi tercih edilmiştir. Optimizasyon PuLP kütüphanesinde gerçeklenirken ticari CPLEX çözücüsü kullanılmıştır. Benzetim çalışmasında $\Delta T$ birim zaman aralığ $5 \mathrm{dk}$ olarak kabul edilmiştir.

Akıllı evde 4 kişilik bir ailenin yaşadığı ve ebeveynlerin ikisinin de çalıştığı varsayılmıştır. Oluşturulan senaryoya göre sabah 07:00'da tüketimin başladığı ve duş almanın da gerçekleşmesi sonucu hem elektrik hem de sıcak su tüketiminin arttığı düşünülmüştür. Bu etkinliklerin saat 07:30'a kadar sürdüğü varsayılmıştır. 07:30 ve 17:45 aralığında akıllı evde sadece buzdolabı ve derin dorundurucu gibi sabit ve sürekli çalıştığı varsayılan yüklerin güç tüketimi gerçekleştirdiği düşünülmüştür. Yine saat 00:05 ve 07:00 aralığında da benzeri bir profil söz konusudur. Bahsi geçen saatlerin dışında kalan zaman aralıklarında ise yani 17:45 ve 00:00 aralığında televizyon, bilgisayar, çamaşır makinası, bulaşık makinası, firın, lamba ve ütü gibi elektrikli ev aletlerinin çalıştığı ve güç tüketiminin pik yaptığı saatler olarak karşımıza çıkmıştır. Kritik yüklerin enerji talep grafiği Şekil 6'da gösterilmiştir.

Bu çalışmada, evsel kullanıcı talep cevabı programına katılım gösterirken dinamik fiyatlandırma sisteminin verileri giriş verisi olarak sağlanmıştır. Birim elektrik enerjisinin fiyatı EPİAŞ gün öncesi piyasası takas değerleri (EPİAŞ, 2020, 1 Ocak) baz alınarak veri seti oluşturulmuştur. İlgili dinamik fiyatlandırma eğrisi Şekil 7'de gösterilmiştir.

Klimanın çalışmasını yönetebilmek için evin eşdeğer termal direncinin ve iç ortam hava kütlesinin hesaplanması gerekmektedir. Akıllı evin eşdeğer termal direnci evde kullanılan malzemelerin termodinamik özelliklerine, evin yapısına ve camlarda ve duvarlarda kullanılan malzemenin özelliklerine bağlı olarak değişmektedir. İç ortam hava kütlesi $\left(m_{h}\right)$ ise evin hacmi $\left(V_{e v}\right)$ ve havanın yoğunluğu $\left(\delta_{\text {hava }}\right)$ ile doğru orantılıdır. Termodinamiksel bu özelliklere ait hesaplamalar (Paterakis vd., 2015) çalışma baz alınarak (10)-(12) eşitlikleri sayesinde oluşturulmuştur.

$$
\begin{gathered}
R^{e s}=\frac{1}{N} \sum_{i} \frac{l_{i}}{\sigma_{i} A_{i}} \\
V_{e v}=L_{1} \cdot L_{2} \cdot L_{3}+\tan (\beta) \cdot L_{1} \cdot L_{2} \\
m_{h}=V_{e v} \cdot \delta_{\text {hava }}
\end{gathered}
$$




\section{European Journal of Science and Technology}

Genelde havanın yoğunluğu ve 1sı kapasitesi gibi özellikler sıcaklık ve basınç gibi termodinamiksel etkenlere bağgl olarak değişmektedir. Bu çalışmada ilgili değerler sabit ve standart olarak $\delta_{\text {hava }}=1,225 \mathrm{~kg} / \mathrm{m}^{3}$ ve $c_{a}=1,01 \mathrm{~kJ} / \mathrm{kg} .{ }^{\circ} \mathrm{C}$ şeklinde kabul edilmiştir. Evin yapısal özellikleriyle ilgili parametreler Tablo 1'de gösterilmiştir. Verilen denklemler ve parametrelere göre eşdeğer termal direnç $\left(R^{e s}\right) ; 3,1965 \cdot 10^{-6} \mathrm{~h} .{ }^{\circ} \mathrm{C} / \mathrm{J}$, evin hacmi $\left(V_{e v}\right) ; 1451,729 \mathrm{~m}^{3}$, havanın ağırlığı $\left(m_{h}\right) ; 1778,369 \mathrm{~kg}$ olarak hesaplanmıştır. Bununla birlikte klimanın anma gücü $\left(R_{k}\right) 2 \mathrm{~kW}$ ve performans verimliliği (COP) 2 olarak kabul edilmiştir. Bütün değerler (Paterakis vd., 2015) referans çalışma baz alınarak dikkate alınmıştır. Belirlenen kış günü için gün içi sıcaklık değişimi İstanbul saatlik tahmin verilerinden uyarlanarak elde edilmiş ve Şekil 8'de gösterilmiştir (AccuWeather, 2020, 1 Ocak). Belirlenen kış günü için ışıma değerleri $\left(S_{t}\right)$ ise İstanbul için öngörülen saatlik ışıma verilerinden uyarlanarak elde edilmiş olup Şekil 9'da gösterilmiştir (Global Solar Atlas, 2020, Ocak).

Su 1sıtma sisteminin optimizasyonu için su tüketimiyle ilgili senaryo (Paterakis vd., 2015) referansa uygun şekilde gerçekleştirilmiştir. Her bir duş süresi $10 \mathrm{dk}$ (2 periyot) alınmış olup, su tüketimi $8 \mathrm{~kg} / \mathrm{dk}$ olarak öngörülmüştür. Gün içerisindeki duş zamanları 18:45, 19:00, 6:20 ve 6:35 saatleri olacak şekilde varsayılmıştır. İlgili referansa uygun şekilde duş sirasında su sıcaklığının $40^{\circ} \mathrm{C}$ 'nin altına düşmemesi istenmiş ve güvenlik sınırı $60^{\circ} \mathrm{C}$ olarak belirlenmiştir. Ek olarak referansa bağlı kalınarak klima ve tank suyu sıcaklığının termal etkileşimde olmadığı kabul edilmiştir.

Kazan suyunun istenilen değerlerde tutulması için önerilen (5) nolu denklemde kullanılan parametrelerle ilgili veriler (Medeiros vd., 2013)'deki kullanılan verilerle orantılı seçilmiştir. Bu parametre değerleri Tablo 2'de gösterilmiştir. (Czech Brewery System) kazan tipi örnek alınarak 600 L'lik kazan için toplam yüzey alanı $(A)$ 4,65 $\mathrm{m}^{2}$ alınmıştır. (Kalogirou, 2009, Ex: 3.6) verilen örneğe uygun şekilde güneş kollektörü yüzey alanı $\left(A_{c}\right) 4,8 \mathrm{~m}^{2}$ ve güneş kollektörü ve hava arasındaki 1sı kaybı katsayısı $\left(U_{l}\right) 0,024 \mathrm{~W} / \mathrm{m}^{2}{ }^{\circ} \mathrm{C}$ olarak hesaba katılmışırır.

\subsection{Sonuç ve Tartışma}

Yapılan modelleme sonucunda iç ortam sıcaklı̆̆ının değişimi Şekil 10 ile gösterilmiştir. Bu sıcaklık değerinin gün boyunca maksimum ve minimum değerler arasında değiştiği ve bunları kesinlikle aşmadığı görülmektedir. Saat 09:30-10:10 arasında hem fiyatın hem de yüklenmenin en düşük değerlerde olması sonucu klimanın çalıştırıldığını ve sıcaklığın maksimum izin verilen sınıra yaklaştığı görülmüştür. Burada amaç, sıcaklı̆̆ kullanıcı tarafından belirlenen sınırlar arasında tutarken kayıpların minimize olmasını sağlamaktır. Diğer bir yandan, saat 17:10-23:00 aralığında hem fiyatların yükselmesi hem de tüketimin artması nedeniyle klima kullanımının asgari şekilde sürdürüldüğü (sadece konfor kısıtlarının aşılmaması sağlanarak) görülmüştür. Dış ortamdaki hava koşulları ve termodinamik kanunlar gereğince yaşanan ısı kayıpları iç ortam sıcaklığını düşürme eğilimi gösterirken klima, bu noktada kullanıcı konfor kısıtlarını dikkate alacak şekilde sıcaklığı dengeleme üzerine bir çalışma sergilemiştir. Yani talep tarafında klimanın yönetilmesi aslında hem güç sistem işletimi açısından fayda sağlamakla birlikte kullanıcıların da özellikle konfor noktasında bir kayıp yaşamaması bu tarz programlara katılımın artmasına fayda sağlamaktadır. Güneş kollektörü, ışıma ile aldığı güneş enerjisini kayıplar ve verimlilik oranı doğrultusunda belli bir güç değeri şeklinde suya aktarır. Şekil 11'de kollektörün, ışıma değerlerine karşılık gelen güç aktarım kapasitesi görülmektedir. Güneş kollektöründen elde edilen güç değerleri güneş 1şımasının yoğun olduğu saatlerde artı̧̧ gösterirken, güneş batmasıyla beraber 0 değerinde seyretmektedir.

Şekil 12'de kazan suyu sıcaklığının değişimi gösterilmiştir. Yapılan işletim sayesinde sıcaklık değerlerinin belirlenen alt limit ve üst limiti aşmadığı gözlemlenmiştir. Saat 09:00-13:00 aralığında sıcaklığın artış gösterdiği görülmektedir. Sebebi güneş kollektörünün en verimli saatlerini geçiriyor olmasıdır. Şekil 12 ve 13 ortak olarak gösterildiği şekliyle gece saatlerinde su sıcaklığı belirlenen limitin altına düşmeyecek şekilde minimum değerlerde seyretmektedir. Sabah evsel kullanıcılar için belirlenen duş saatlerinden önce elektrikli şofben vasıtası ile kazan suyu sıcaklığının yükseltildiği görülmektedir. Aynı zamanda duşta kullanılan suyun sıcaklığına ve miktarına bağlı olarak duş vakitlerinin sonunda kazan suyu sıcaklıklarının düş̧üğü görülmektedir.

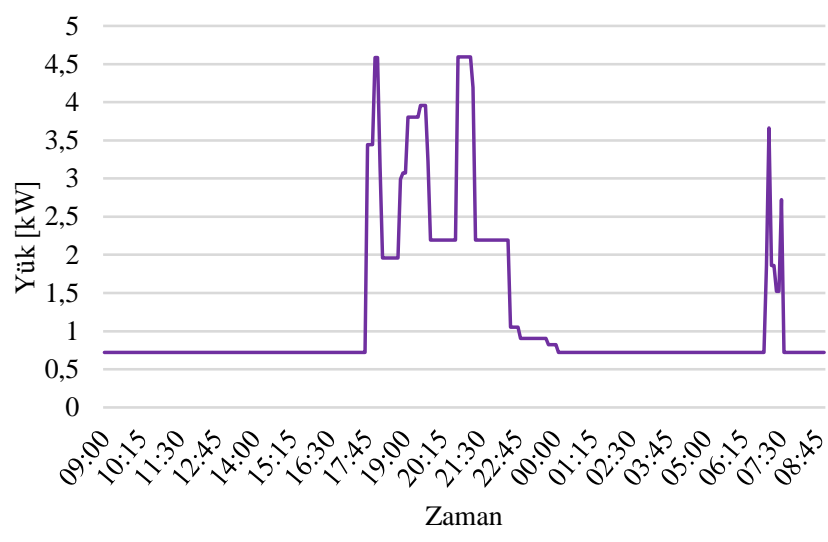

Şekil 6. Akıllı Evin Kritik Yük Ĕgrisi

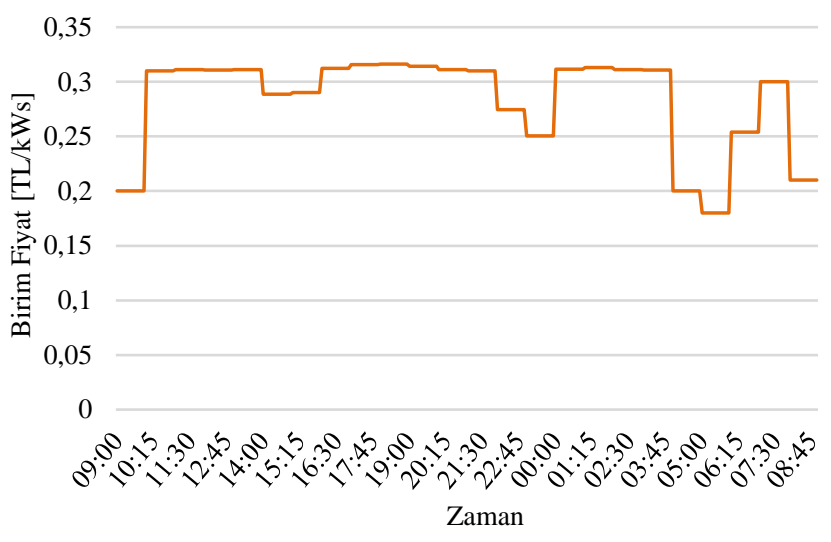

Şekil 7. Elektrik Satın Alım Birim Fiyatı 


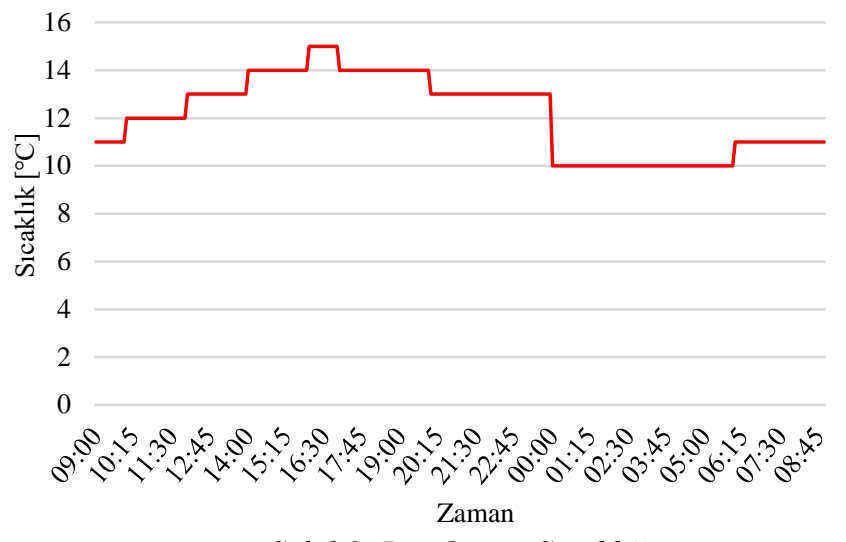

Şekil 8. Dış Ortam Sicaklı̆̆

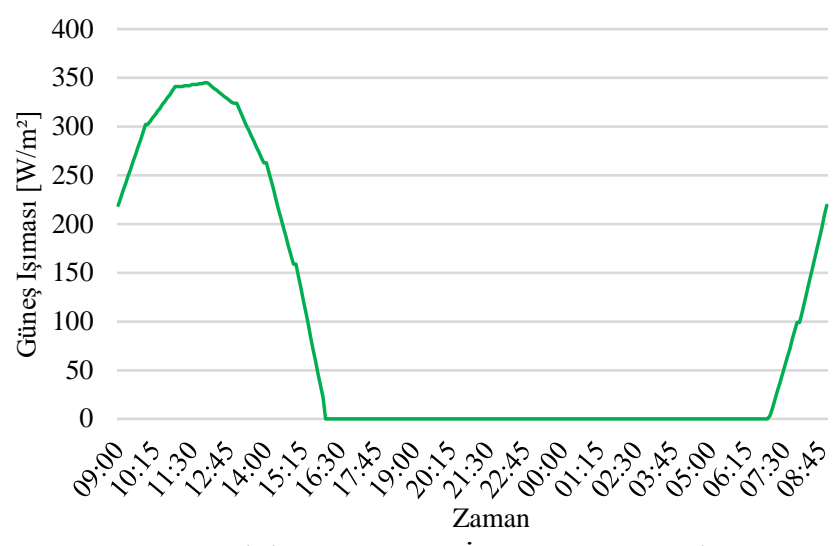

Şekil 9. Kış Günü İçin Işıma Değerleri

Tablo 1. Evin Yapısal Özellikleri

\begin{tabular}{lcc|lccc}
\hline Parametre & Değer & Birim & Parametre & Değer & Birim \\
\hline Evin Uzunluğu $\left(L_{1}\right)$ & 30 & $\mathrm{~m}$ & Pencere Alanı & 1 & $\mathrm{~m}{ }^{2}$ & \\
\hline Evin Genişliği $\left(L_{2}\right)$ & 10 & $\mathrm{~m}$ & Duvar Termal Verimliliği & 136,8 & $\mathrm{~J} / \mathrm{s} . \mathrm{m} .{ }^{\circ} \mathrm{C}$ \\
\hline Evin Yüksekliği $\left(L_{3}\right)$ & 4 & $\mathrm{~m}$ & Pencere Termal Verimliliği & 2808 & $\mathrm{~J} / \mathrm{s} . \mathrm{m} .{ }^{\circ} \mathrm{C}$ \\
\hline Çatı Açısı $(\beta)$ & 40 & $\mathrm{deg}$ & Pencere Kalınlığ & 0,05 & $\mathrm{~m}$ \\
\hline Pencere Sayısı & 6 & - & Duvar Kalınlığ & 0,15 & $\mathrm{~m}$ \\
\hline
\end{tabular}

Tablo 2. Su Isıtma Sistemini Özellikleri

\begin{tabular}{lcc|lcc}
\hline Parametre & Değer & Birim & Parametre & Değer & Birim \\
\hline $\begin{array}{l}\text { Kazan ve hava arasındaki 1S1 } \\
\text { kaybı katsayısı }(U)\end{array}$ & 5 & $\mathrm{~W} / \mathrm{m}^{2}{ }^{\circ} \mathrm{C}$ & $\begin{array}{l}\text { Ortalama Soğuk Su } \\
\text { Sicaklığı }\left(T_{t}^{s}\right)\end{array}$ & 8 & ${ }^{\circ} \mathrm{C}$ \\
\hline $\begin{array}{l}\text { Güneş kollektörü 1s1 } \\
\text { soğurma faktörü }\left(F_{r}\right)\end{array}$ & 0,75 & - & Kazan suyu ağırlığı $\left(m_{s}\right)$ & 600 & $\mathrm{~kg}$ \\
\hline Suyun öz 1Sısı $\left(c_{p}\right)$ & 1,16 & $\mathrm{Ws} / \mathrm{kg}{ }^{\circ} \mathrm{C}$ & $\begin{array}{l}\text { Elektrikli şofbenin anma } \\
\text { gücü }\left(Q_{c}\right)\end{array}$ & 10 & $\mathrm{~kW}$ \\
\hline
\end{tabular}

Şekil 12'de kazan suyu sıcaklığının değişimi gösterilmiştir. Yapılan işletim sayesinde sıcaklık değerlerinin belirlenen alt limit ve üst limiti aşmadığı gözlemlenmiştir. Saat 09:00-13:00 aralığında sıcaklığın artış gösterdiği görülmektedir. Sebebi güneş kollektörünün en verimli saatlerini geçiriyor olmasıdır. Şekil 12 ve 13 ortak olarak gösterildiği şekliyle gece saatlerinde su sıcaklığı belirlenen limitin altına düşmeyecek şekilde minimum değerlerde seyretmektedir. Sabah evsel kullanıcılar için belirlenen duş saatlerinden önce elektrikli şofben vasıtası ile kazan suyu sıcaklığının yükseltildiği görülmektedir. Aynı zamanda duşta kullanılan suyun sıcaklığına ve miktarına bağlı olarak duş vakitlerinin sonunda kazan suyu sıcaklıklarının düştüğü görülmektedir.

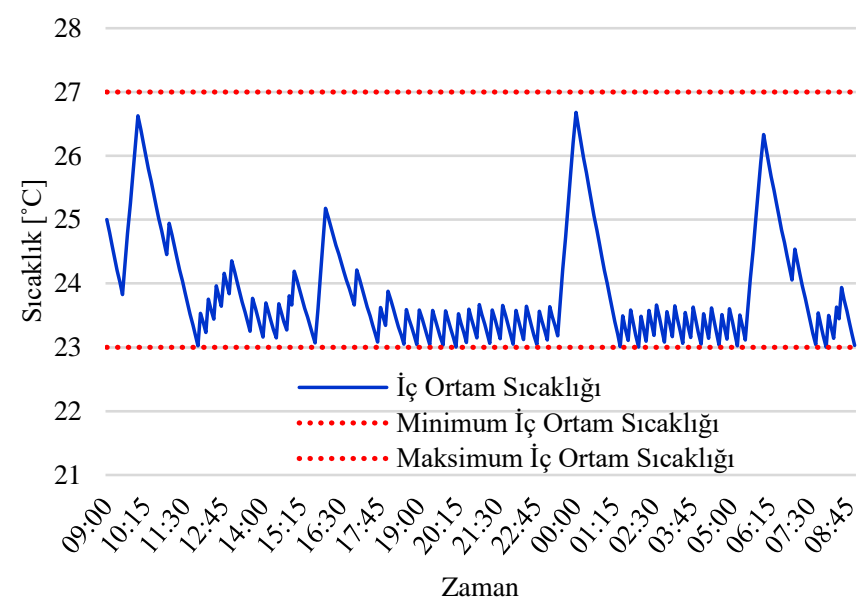

Şekil 10. İç Ortam Sicaklı̆̆l

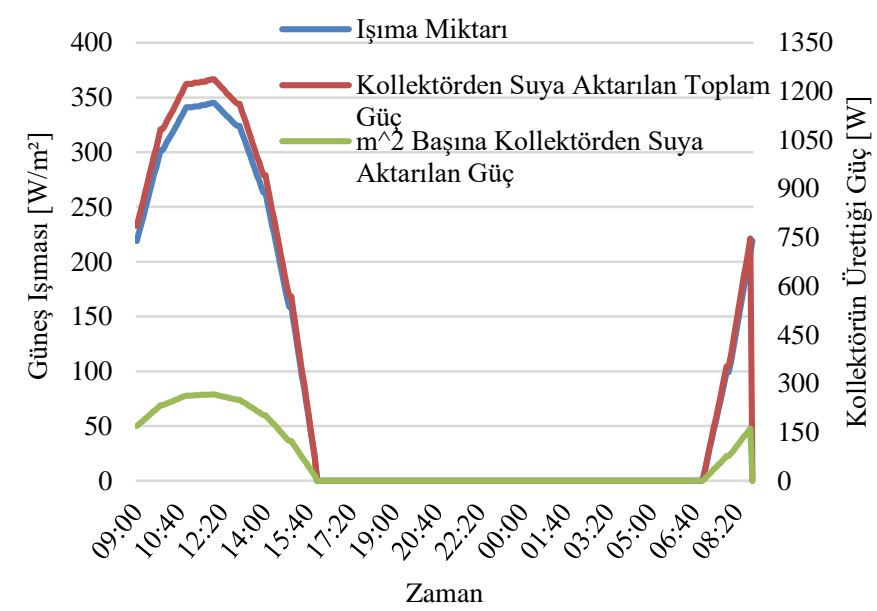

Şekil 11. Güneş Işıma Miktarlar, Kollektörden Suya Aktarılan Toplam Güç ve $m^{2}$ Başına Suya Aktarllan Güç 


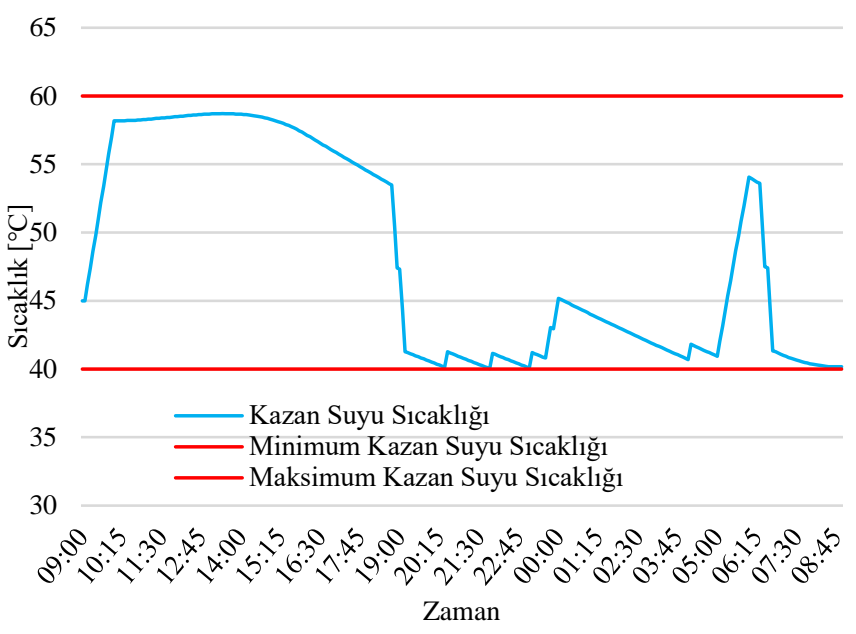

Şekil 12. Kazan Suyu Sicakllğgl

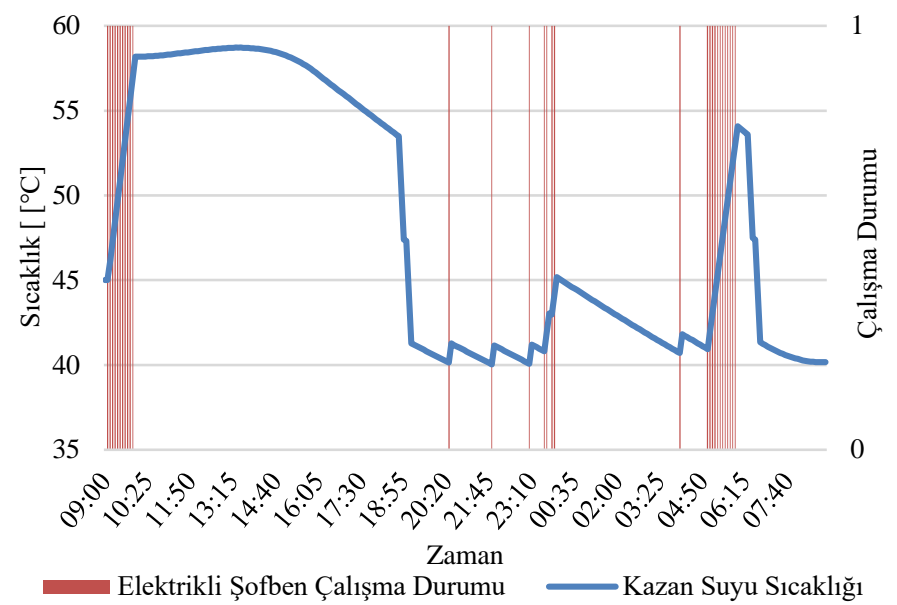

Şekil 14. Elektrikli Şofben Çalışma Durumuna Bă̆gl Kazan Suyu Sicaklığ

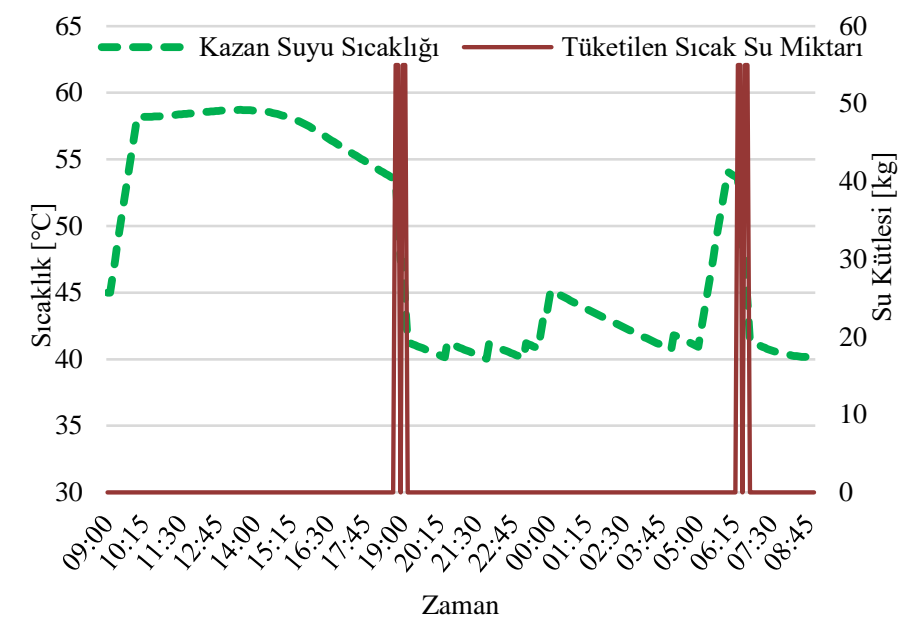

Şekil 13. Tüketilen Sıcak Su Miktarın Karşılık Kazan Suyu Sicaklığının Değişimi

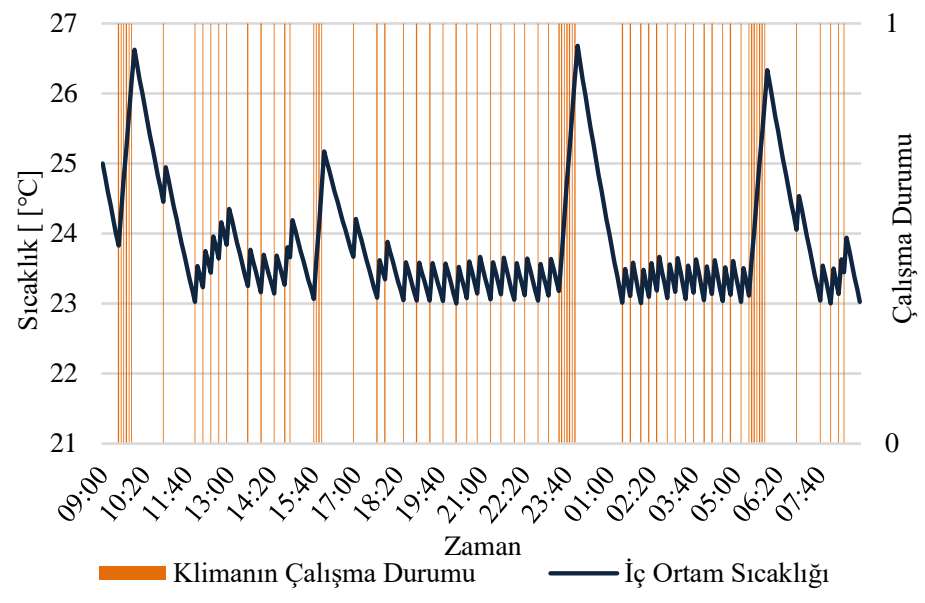

Şekil 15. Klima Çalışma Durumuna Bağgl İ̧̧ Ortam Sicaklı̆̆

Geliştirilen enerji yönetim algoritmasında talep cevabı stratejilerinin etkilerini inceleyebilmek amacıyla Şekil 14 ve Şekil 15 'te sırasıyla elektrikli şofbenin çalışma durumuna bağlı olarak kazan suyu sıcaklığı ve yine klimanın devrede olup olmamasına göre değişen iç ortam sıcaklığı gösterilmiștir. İlgili evsel cihazların devreye alınıp alınmaması 1 ve 0 değerleri ile modellenmiștir. Beklendiği üzere ilgili cihazlar devreye alındığında sıcaklıkların yükseldiği görülmüştür. Kazan suyu sıcaklığı, elektrikli şofbenin saat 09:00-10:00 ve 05:00-06:00 zaman aralıklarında yoğun çalışması sonucu yüksek oranda artmıştır. Bunun yanı sıra iç ortam sıcaklığı da klimanın 09:3010:00, 15:40-16:00, 23:25-23:55 ve 05:25-05:55 periyotlarında keskin şekilde pozitif yönde artışlara neden olmuştur.

Optimizasyon algoritmasının çalışma prensibini ve etkinliğini daha net bir şekilde vurgulamak amacı enerji yönetim sistemi olmadan temel durum analizi gerçekleştirilmiştir. Bu analize göre klimanın, iç ortam sıcaklığı 25 derecenin altında iken çalışıı̆̆ 25 derecenin üstüne çıktı̆̆ında ise kapanacak şekilde ayarlandığı Şekil 16'da görülmüştür. Optimizasyon tabanlı yaklaşımda, klimanın çalışması enerji fiyatlandırmasına, yükün değişimine bağlı olarak belirlendiği iç̧in daha esnek çalışma saatlerine sahip olduğu söylenebilir. Bunun sonucu olarak da iç ortam sıcaklığının sadece 25 derece bandında seyretmesinden ziyade kullanıcı konfor kısıtları dâhilinde farklı aralıklarda ayarlanabilme imkânı sunulmuştur. Şekil 17 ile enerji yönetimi mekanizmasının dikkate alındığı ve devre dışı bırakıldığı durumlardaki (temel durum) kazan suyu sıcaklığının değişimi gösterilmiştir. Burada, kazan suyu sıcaklı̆̆ belirlenen duş saatinde beklenildiği üzere 45 derecenin altına düşmüştür. Güneş kollektörünün göz ardı edildiği durumda elektrikli şofben, kazan suyu sıcaklı̆̆ı 45 derecenin altında iken çalışmış ve 45 derecenin üstüne çıktığında ise kapanmıştır.

Şekil $18^{\prime}$ de ise dikkate alınan akıllı evin günlük yük eğrisi gösterilmiştir. Enerji yönetim sistemine katılmayan kritik yüklerin sabahın ilk saatlerinde kullanılmaya başlandığını ve eve geliş zamanından gün sonuna kadar geçen sürede ise artış gösterdiğini ve diğer zamanlarda buzdolabı ve dondurucu gibi çalı̧̧ması sürekli devam eden ev aletlerinin az miktartarda güç tüketimine neden olduğu görülmüş̧ür. Yapılan optimizasyon bazlı enerji yönetim stratejisine göre, klima ve elektrikli şofben yüklerinin saat 09:00-10:00, 23:3000:00 ve 05:00-06:00 aralıklarında kullanımlarının arttığı ölçülmüştür. Yüklerin gösterdiği bu davranışlar sonucunda elde edilen optimizasyon yaklaşımına göre belirlenen yüklerin kontrolü sağlanarak elektrik enerjisi maliyetinin düşürülmesi amacına ulaşıldığı net olarak görülmüştür. 


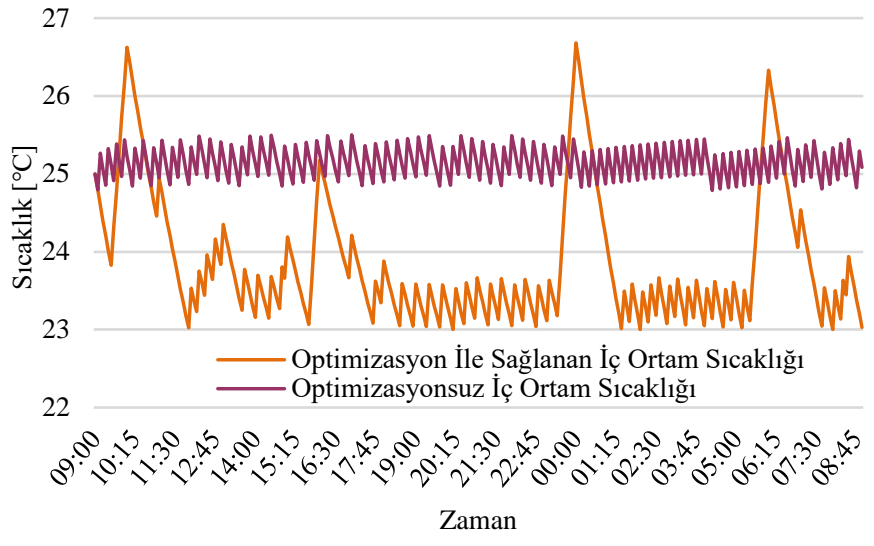

Şekil 16. İç Ortam Sicaklı̆̆ının Değişimi

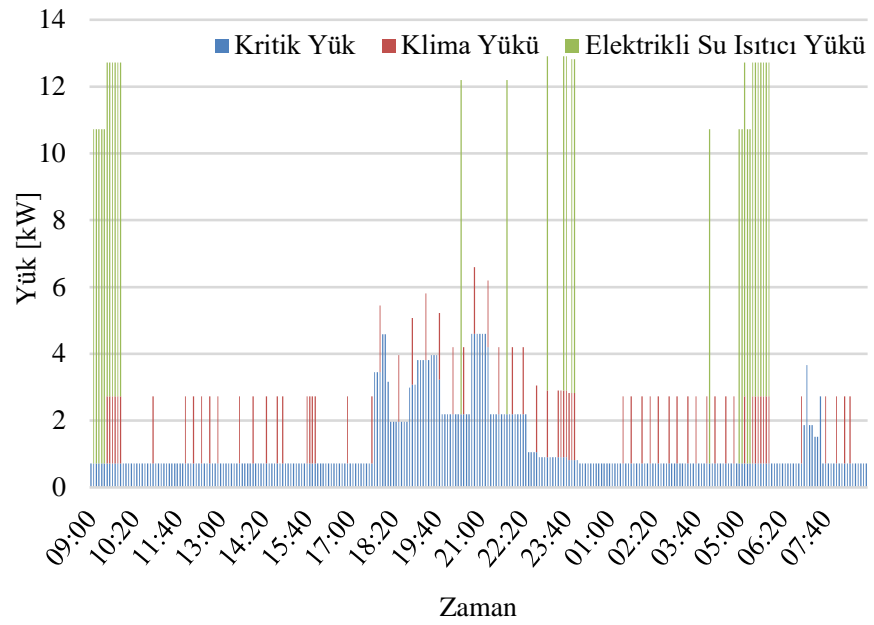

Şekil 18. Akıllı Evin Yük Ë̆risi

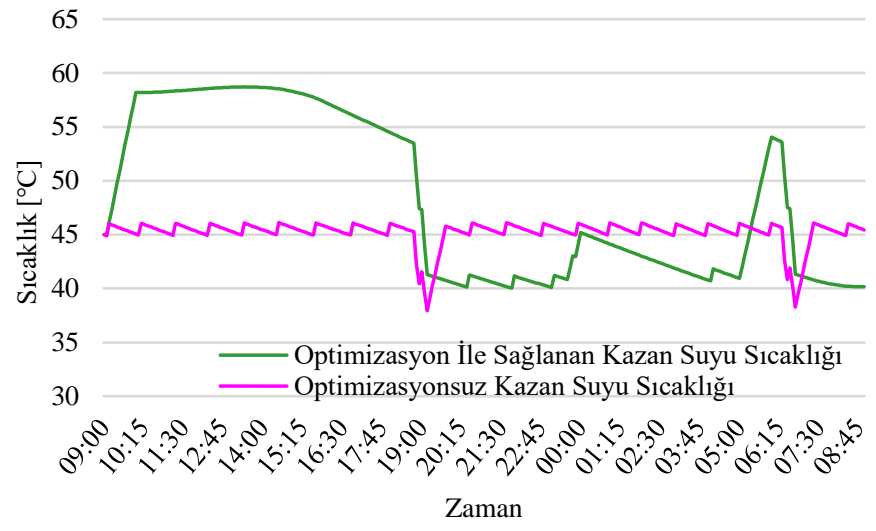

Şekil 17. Optimizasyon ile Kazan Suyu Sicaklı̆̆ı Testi

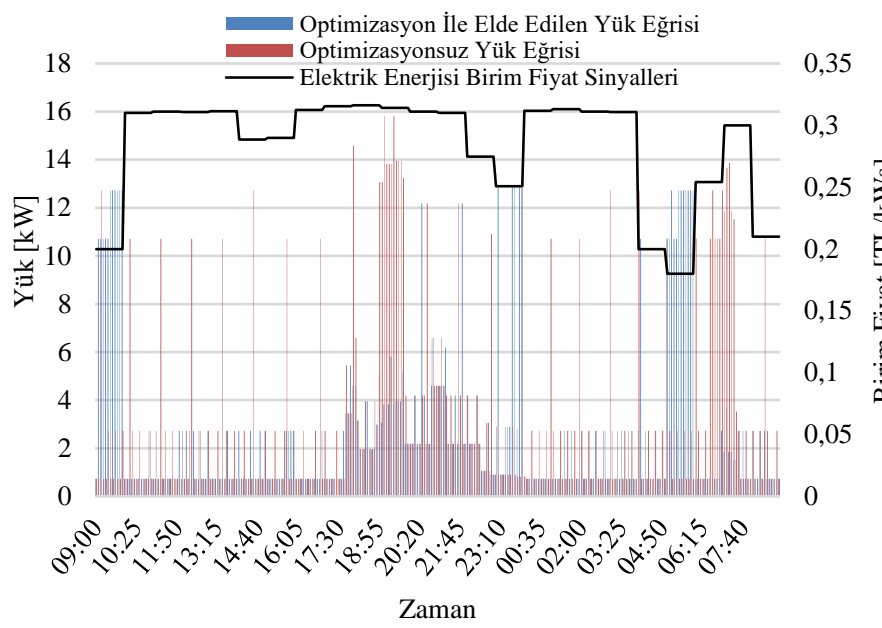

Şekil 19. Optimizasyon ile Yük Testi

Şekil 19'da akıllı evin yük tüketim eğrisi ve elektrik enerjisi alım fiyatıyla birlikte iki farklı senaryoya bağlı olarak gösterilmiştir. Optimizasyon programı kullanılarak oluşturulan enerji yönetimine yönelik çalışmada, normal tüketim profiline göre yüklerin, kullanıcı konfor kısıtlarını aşmadan elektrik enerjisi birim fiyatının düşük olduğu zaman dilimlerine ötelenmesi beklenmektedir. Yük profilleri ve elektrik enerjisi birim fiyatı eğrisi üst üste konularak incelendiğinde optimizasyon algoritmasının çalıştırılmadığ 1 durumda fiyatlandırmaya bağlı olmadan bir eğrinin meydana geldiği görülmüştür. Oysa ki maliyeti minimize edecek şekilde belirlenen amaç fonksiyonuna göre geliştirilen optimizasyon algoritması sayesinde fiyatın yüksek olduğu periyotlarda tüketimin azalma eğiliminde ve fiyatın düşük olduğu zaman aralıklarında ise güç tüketiminin arttığı gösterilmiştir. Grafiğe göre kontrol edilebilir yükler doğrudan dinamik fiyatlandırmaya bağlı olarak saat 09:00-10:00, 23:30-00:00 ve 05:00-06:00 aralıklarında çalışmaktadır. Bu bağlamda, geliştirilen akıllı ev enerji yönetim sistemi sayesinde son kullanıcının toplam maliyeti minimize edilecek şekilde bir yük devreye alma ve devreden çıkarma aksiyonları geliştirilerek talebin kontrolü sağlanmıştır.

\section{Sonuç}

Bu çalışmada, dört kişilik bir ailenin yaşadığı akıllı evde güneş kollektörü vasıtasıyla sıcak su talebi karşılanırken klima ve elektrikli şofben yükünün DR programına katılımı ve böylece talebin şekilledirilmesi hedeflenmiştir. Bu noktada, konfor sınırlamaları göz önünde bulundurularak ısıtma birimlerinin enerji yönetim sistemine sunduğu esnekliğin faydaları araştırılmıştır. Önerilen optimizasyon tabanlı matematiksel programlama, klima ve elektrikli şofbenin tüketim davranışlarında özellikle evsel tüketiciler için yük eğrisine olumlu etkiler yaptığı gözlemlenmiştir. Tek bir akıllı ev dikkate alınmış olsa bile etkileri net bir şekilde grafiklerle desteklenen bu algoritmanın, daha büyük sistemlerde test edilmesi sonucu dağıtım sistem operatörünün operasyonel yeteneğine önemli katkılar sunacağı ve sistem işletme koşullarının iyileştirileceği öngörülmektedir.

Güneş enerjisinden ve optimizasyona dayalı enerji yönetiminden faydalanılan bu sistemde yenilenebilir kaynakların ve efektif bir enerji yönetiminin evsel tüketicinin elektrik enerjisi maliyetine etkileri ortaya koyulmuştur. Güneş kollektörü ve optimizasyon algoritması sayesinde elektrikli şofbenin bir günlük toplam tüketimi 34,986 kWh’ten 25,823 kWh'e düşürülmüştür. Kollektörün, elektrikli şofbenin tüketimine olan bu etkisi faturaya aylık olarak ortalama 80 TL olarak yansıyacaktır. Akıllı evin kritik yükleriyle beraber klima ve elektrikli şofbenin tüketimleri göz önünde bulundurulduğunda optimizasyon işletimi sayesinde faturada \%24 oranında bir düşme sağlanmıştır. Bu sonuçlar, enerji yönetim sistemlerinin teknolojiyle beraber günlük hayatımıza entegre olmasının ne kadar kritik bir önemine sahip olduğunun altını çizmektedir. 


\section{European Journal of Science and Technology}

Bundan sonra gerçekleştirilmesi planlanan çalışmalarda enerji yönetimindeki esnekliğe evin diğer yüklerinin ve enerji depolama sistemlerinin dahil edilmesi ve optimizasyon modellemesinin gerçek zamanlı fiyatlandırma politikalarıyla entegre olabilmesi üzerinde durulacaktır.

\section{Teșekkür}

Teknik desteklerinden ötürü Nur Betül Yaman'a ve kreatif iconlarını çalışmamıza eklediğimiz takma isimleri DinosoftLabs, Freepik, Icongeek26, Smallikeart ve Smashicons olan yazarlara teşekkür ederiz.

\section{Kaynakça}

AccuWeather. (2020, 1 Ocak). İstanbul Hava Durumu. Erişim Adresi:

https://www.accuweather.com/en/tr/istanbul/318251/hourly-weather-forecast/318251?day=2

Ahmed, M. S., Mohamed, A., Homod, R. Z., Shareef, H., \& Khalid, K. (2016). Modeling of electric water heater and air conditioner for residential demand response strategy. International Journal of Applied Engineering Research, 11(16), 9037-9046.

Ali, S. M. H., Lenzen, M., \& Tyedmers, E. (2019). Optimizing 100\%-renewable grids through shifting residential water-heater load. International Journal of Energy Research, September 2018, 1-15. https://doi.org/10.1002/er.4416

Alvina, P., Bai, X., Chang, Y., Liang, D., \& Lee, K. (2017). Smart Community Based Solution for Energy Management: An Experimental Setup for Encouraging Residential and Commercial Consumers Participation in Demand Response Program. Energy Procedia, 143, 635-640. https://doi.org/10.1016/j.egypro.2017.12.739

Behrangrad, M. (2015). A review of demand side management business models in the electricity market. Renewable and Sustainable Energy Reviews, 47, 270-283. https://doi.org/10.1016/j.rser.2015.03.033

Cai, M., Ramdaspalli, S., Pipattanasomporn, M., Rahman, S., Malekpour, A., \& Kothandaraman, S. R. (2019). Impact of HVAC Set Point Adjustment on Energy Savings and Peak Load Reductions in Buildings. 2018 IEEE International Smart Cities Conference, ISC2 2018, 1-6. https://doi.org/10.1109/ISC2.2018.8656738

ComEd. Central Air Conditioning Cycling Program. Erişim Adresi:

https://www.comed.com/WaysToSave/ForYourHome/Pages/CentralACCycling.aspx

Chiu, T. C., Shih, Y. Y., Pang, A. C., \& Pai, C. W. (2017). Optimized Day-Ahead Pricing with Renewable Energy Demand-Side Management for Smart Grids. IEEE Internet of Things Journal, 4(2), 374-383. https://doi.org/10.1109/JIOT.2016.2556006

Czech Brewery System. HWT-600 Sicak Su Deposu 600 Litre. Erişim Adresi:

https://eshop.czechminibreweries.com/tr/product/hwt-600/

Enerji Piyasaları İşletme A.Ş. (2020, 1 Ocak). Piyasa Takas Fiyatı. Erişim Adresi:

https://seffaflik.epias.com.tr/transparency/piyasalar/gop/ptf.xhtml

Erol-Kantarci, M., \& Mouftah, H. T. (2011). Wireless multimedia sensor and actor networks for the next generation power grid. $A d$ Hoc Networks, 9(4), 542-551. https://doi.org/10.1016/j.adhoc.2010.08.005

Facão, J. (2016). Optimization of flow distribution in flat plate solar thermal collectors with riser and header arrangements. Solar Energy, 120, 104-112. https://doi.org/10.1016/j.solener.2015.07.034

Freegah, B., \& Al-Tabbakh, A. A. (2019). Experimental and numerical analysis of a thermosyphon solar water heater for domestic applications. UPB Scientific Bulletin, Series D: Mechanical Engineering, 81(1), 117-132.

Gaur, G. (2016). A Review on Demand Side Management Solutions for Power Utilities. 9829-9834. https://doi.org/10.15680/IJIRSET.2015.0506043

Gautam, A., Chamoli, S., Kumar, A., \& Singh, S. (2017). A review on technical improvements, economic feasibility and world scenario of solar water heating system. Renewable and Sustainable Energy Reviews, 68(August 2016), 541-562. https://doi.org/10.1016/j.rser.2016.09.104

Global Solar Atlas. (2020, Ocak). Bahcelievler İstanbul. Erişim Adresi:

https://globalsolaratlas.info/detail?c $=41.157978,28.506775,9 \& \mathrm{~s}=41.004775,28.825378 \& \mathrm{~m}=$ site $\& p v=$ small, $180,31,1$

Godina, R., Rodrigues, E. M. G., Pouresmaeil, E., \& Catalão, J. P. S. (2017). Home HVAC energy management and optimization with model predictive control. Conference Proceedings - 2017 17th IEEE International Conference on Environment and Electrical Engineering and 2017 1st IEEE Industrial and Commercial Power Systems Europe, EEEIC / I and CPS Europe 2017, 309048, 7 11. https://doi.org/10.1109/EEEIC.2017.7977766

Godina, R., Rodrigues, E. M. G., Pouresmaeil, E., Matias, J. C. O., \& Catalão, J. P. S. (2018). Model Predictive Control home energy management and optimization strategy with demand response. Applied Sciences (Switzerland), 8(3). https://doi.org/10.3390/app8030408

Goh, C. H. K., \& Apt, J. (2005). Consumer Strategies for Controlling Electric Water Heaters under Dynamic Pricing. Carnegie Mellon Electricity Industry Center Working Paper, 1-8.

Güngör, V. C., Sahin, D., Kocak, T., Ergüt, S., Buccella, C., Cecati, C., \& Hancke, G. P. (2011). Smart grid technologies: Communication technologies and standards. IEEE Transactions on Industrial Informatics, 7(4), 529-539. https://doi.org/10.1109/TII.2011.2166794

Hungerford, Z., Bruce, A., \& MacGill, I. (2016). Review of demand side management modelling for application to renewables integration in Australian power markets. Asia-Pacific Power and Energy Engineering Conference, APPEEC, 2016-January. https://doi.org/10.1109/APPEEC.2015.7381083

Jouhara, H., \& Yang, J. (2018). Energy efficient HVAC systems. Energy and Buildings, 179, 83-85. https://doi.org/10.1016/j.enbuild.2018.09.001 
Kalogirou, S. A. (2009). Solar Energy Collectors. 121-217. https://doi.org/10.1016/B978-0-12-374501-9.00003-0

Koltsaklis, N. E., Panapakidis, I. P., Christoforidis, G. C., \& Parisses, C. E. (2019). An MILP model for the optimal energy management of a smart household. International Conference on the European Energy Market, EEM, 2019-September, 1-6. https://doi.org/10.1109/EEM.2019.8916426

Lokeshgupta, B., \& Sivasubramani, S. (2019). Multi-objective home energy management with battery energy storage systems. Sustainable Cities and Society, 47(February), 101458. https://doi.org/10.1016/j.scs.2019.101458

Mahin, A. U., Sakib, M. A., Zaman, M. A., Chowdhury, M. S., \& Shanto, S. A. (2017). Developing demand side management program for residential electricity consumers of Dhaka city. ECCE 2017 - International Conference on Electrical, Computer and Communication Engineering, 743-747. https://doi.org/10.1109/ECACE.2017.7913001

McKinsey \& Company. (2019). Global Energy Perspective 2019 : Reference Case. Energy Insights, January, 31.

Medeiros, M., Nogueira, C. E. C., Siqueira, J. A. C., Lawder, J. H., de Souza, S. N. M., \& Fracaro, G. de P. M. (2013). Otimização de um sistema misto de aquecimento de água (solar e elétrico) para áreas rurais. Acta Scientiarum - Technology, 35(1), 69-74. https://doi.org/10.4025/actascitechnol.v35i1.11998

Meyabadi, A. F., \& Deihimi, M. H. (2017). A review of demand-side management: Reconsidering theoretical framework. Renewable and Sustainable Energy Reviews, 80(May), 367-379. https://doi.org/10.1016/j.rser.2017.05.207

Mohsenian-Rad, A. H., \& Leon-Garcia, A. (2010). Optimal residential load control with price prediction in real-time electricity pricing environments. IEEE Transactions on Smart Grid, 1(2), 120-133. https://doi.org/10.1109/TSG.2010.2055903

Ovoenergy. How much electricity does a home use?. Erişim Adresi: https://www.ovoenergy.com/guides/energy-guides/how-muchelectricity-does-a-home-use.html

Paterakis, N. G., Medeiros, M. F., Catalao, J. P. S., Siaraka, A., Bakirtzis, A. G., \& Erdinc, O. (2015). Optimal daily operation of a smart-household under dynamic pricing considering thermostatically and non-thermostatically controllable appliances. International Conference on Power Engineering, Energy and Electrical Drives, 2015-September, 389-393. https://doi.org/10.1109/PowerEng.2015.7266348

Perez, K. X., Baldea, M., \& Edgar, T. F. (2016). Integrated HVAC management and optimal scheduling of smart appliances for community peak load reduction. Energy and Buildings, 123, 34-40. https://doi.org/10.1016/j.enbuild.2016.04.003

Pipattanasomporn, M., Member, S., Kuzlu, M., \& Rahman, S. (2012). 2012-06_Tsg_Hem. 1-8.

REN21. (2019). Renewables 2019. October, 335.

Safdarian, A., Ali, M., Fotuhi-Firuzabad, M., \& Lehtonen, M. (2016). Domestic EWH and HVAC management in smart grids: Potential benefits and realization. Electric Power Systems Research, 134, 38-46. https://doi.org/10.1016/j.epsr.2015.12.021

Santos, A. N., MacAbuhay, M. A. A., \& De Leon, J. N. (2018). Smart household socket with power monitoring control using android application. 2017 9th IEEE-GCC Conference and Exhibition, GCCCE 2017, 1-9. https://doi.org/10.1109/IEEEGCC.2017.8448055

Sempra Energy Utility. AC Saver(Summer Saver) for Business Energy Management Program. Erişim Adresi:

https://www.sdge.com/businesses/savings-center/energy-management-programs/demand-response/summer-saver-program

Schreiber, M., Wainstein, M. E., Hochloff, P., \& Dargaville, R. (2015). Flexible electricity tariffs: Power and energy price signals designed for a smarter grid. Energy, 93, 2568-2581. https://doi.org/10.1016/j.energy.2015.10.067

Siano, P. (2014). Demand response and smart grids - A survey. Renewable and Sustainable Energy Reviews, 30, 461-478. https://doi.org/10.1016/j.rser.2013.10.022

Streicher, W. (2016). Solar Thermal Technologies for Domestic Hot Water Preparation and Space Heating. In Renewable Heating and Cooling: Technologies and Applications. Elsevier Ltd. https://doi.org/10.1016/B978-1-78242-213-6.00002-3

Triki, C., \& Violi, A. (2009). Dynamic pricing of electricity in retail markets. 4or, 7(1), 21-36. https://doi.org/10.1007/s10288-0070056-2

Tsui, K. M., \& Chan, S. C. (2012). Demand response optimization for smart home scheduling under real-time pricing. IEEE Transactions on Smart Grid, 3(4), 1812-1821. https://doi.org/10.1109/TSG.2012.2218835

Wang, H., Meng, K., Luo, F., Dong, Z. Y., Verbič, G., Xu, Z., \& Wong, K. P. (2013). Demand response through smart home energy management using thermal inertia. 2013 Australasian Universities Power Engineering Conference, AUPEC 2013, October. https://doi.org/10.1109/aupec.2013.6725442

Yao, L., Damiran, Z., \& Lim, W. H. (2017). Energy management optimization scheme for smart home considering different types of appliances. Conference Proceedings - 2017 17th IEEE International Conference on Environment and Electrical Engineering and 2017 1st IEEE Industrial and Commercial Power Systems Europe, EEEIC / I and CPS Europe 2017. https://doi.org/10.1109/EEEIC.2017.7977565

Yao, L., Shen, J. Y., \& Lim, W. H. (2017). Real-Time Energy Management Optimization for Smart Household. Proceedings - 2016 IEEE International Conference on Internet of Things; IEEE Green Computing and Communications; IEEE Cyber, Physical, and Social Computing; IEEE Smart Data, IThings-GreenCom-CPSCom-Smart Data 2016, 20-26. https://doi.org/10.1109/iThingsGreenCom-CPSCom-SmartData.2016.31

Zhi, C., Lei, W., \& Yong, F. (2012). Real-Time Price-Based Demand Response Management for Residential Appliances via Stochastic Optimization and Robust Optimization. IEEE Transactions on Smart Grid, 3(4), 1822-1831.

Zhou, L., Zhang, Y., Lin, X., Li, C., Cai, Z., \& Yang, P. (2018). Optimal sizing of PV and bess for a smart household considering different price mechanisms. IEEE Access, 6(c), 41050-41059. https://doi.org/10.1109/ACCESS.2018.2845900 